\title{
A MINIATURIZED RF ACCELERATION MEASURING SYSTEM ${ }^{1}$
}

\author{
D. L. TRAPP \\ Upper Atmosphere Projects Department \\ Sandia Corporation \\ Albuquerque, New Mexico
}

Summary This paper will describe the design and development of a miniaturized highshock package utilizing an FM modulated $19.8 \mathrm{mc}$ transmitter and a piezoresistive accelerometer.

This program was initiated in October 1965 for the purpose of measuring deceleration profiles generated by small diameter (1-1/4 inch) vehicles that penetrate targets of known composition with input velocities up to 1500 feet per second.

Shock levels were anticipated to be in the $0-10,000 \mathrm{~g}$ range, with rise times varying as a function of projectile ogives and anticipated to be as fast as $100 \mu \mathrm{sec}$.

The system was designed to an existing volume described by a right circular cylinder, 1 inch in diameter by 6 inches in length, and an allowable volume of 3/4-inch diameter by 4-inches long was allocated for the $19.8 \mathrm{mc}$ transmitting antenna. The first operational usage of this system was in late January 1966.

Introduction A complicating factor in the design of the system was the necessity for the RF transmission through targets which offered relatively high mitigation of RF carrier frequencies. Loss in efficiencies of up to $60 \mathrm{db}$ were anticipated. This problem, in addition to high shock, led us to the development of the relatively low frequency (19.8 mc) transmitter.

All other system components had to be designed or modified due to the unusual packaging and shock conditions.

In addition to the above, the new system was to be compatible with existing horizontal and vertical sled track facilities and likewise was to have the capability for use in gun environments. Standard FM trailer mounted ground stations were to be utilized.

\footnotetext{
${ }^{1}$ This work was supported by the United States Atomic Energy Commission.
} 
Method of Approach The basic system was laid out as shown in Figure 1.

From previous experience in high-g, fast-risetime shock environments, a decision was made to use a low-source impedance piezoresistive bridge type accelerometer.

The signal conditioning circuit was designed to amplify the 0 - $500 \mathrm{mv}$ signal from the transducer and condition it for the 0 - 5 volt input to a wide-band $70 \mathrm{kc}$ voltagecontrolled oscillator. The VCO would then deviate the $19.8 \mathrm{mc}, 100 \mathrm{mw}$ transmitter approximately $60 \mathrm{kc}$.

An autotransformed loopstick-type antenna was designed to radiate the RF signal.

Power to the system was supplied by a specially designed and packaged water activated silver chloride battery, which provided 24 volts at 100 ma for approximately 30 minutes.

As is shown in Figure 1, the transducer was mounted in the signal conditioning module along with the $70 \mathrm{kc} \mathrm{VCO}$ and this module acted as a wrench for screwing the transducer to the mounting stud. Elco connectors mounted on this module and on the battery module allowed for easy interconnection. A guide pin insured proper connector alignment. A loading ring forcing against the transmitter placed the entire package in high compression. A second loading ring affixed the antenna to the rest of the package.

Component Design and Development The design parameters of the individual components will be described along with their size and performance characteristics. Following this phase of the report will be a discussion of system operation and some typical data will be presented.

\section{A. Piezoresistive Accelerometer}

As a result of previous experience and considerable in-house testing, a decision was made to utilize the Endevco 2261 piezoresistive four-arm bridge type accelerometer. Endevco Corporation was requested to repackage the unit in regard to the type and location of the output cable and connector. This was accomplished and the device was designated 2261M4. (Figure 2).

The decision to use a piezoresistive device was based on the following factors.

1. Low source impedance $(\sim 330 \mathrm{ohm})$, which allowed the use of a relatively low input impedance operational amplifier.

2. Good dynamic response, from DC to $6 \mathrm{kc}$.

3. Good temperature stability in the $0^{\circ} \mathrm{F}$ to $160^{\circ} \mathrm{F}$ temperature range. 
4. High natural frequency of approximately $30 \mathrm{kc}$ which, along with the low source impedance, enabled us to utilize a simple low pass filter $(5 \mathrm{kc})$ for use in gauge resonance situations.

The disadvantages of high excitation power (10 volts, $20 \mathrm{ma}$ ) and low sensitivity $(0.1 \mathrm{mv} / \mathrm{g})$ were not considered to outweigh the advantages of the gauge for this application.

The following are the manufacturer's performance specifications on the 2261M4. A new gauge with a 10,000-g capability will be delivered to Sandia approximately August 30, 1966, for test and evaluation.

\section{Performance Specification \\ 2261-2500-10 Accelerometer}

\section{Scope}

This instrument is a high range piezoresistive accelerometer of the four active arm bridge type. The frequency range extends from static to $6000 \mathrm{cps}$, with low damping and phase shift for observing shock phenomena.

Piezite Type IX semiconductor crystal material is used.

\section{Characteristics}

\subsection{Dynamic}

2.1.1 Range:

2.1.2 Full Scale output with rated excitation

2.1.3 Combined linearity and hysteresis:

2.1.4 Resolution:

2.1.5 Frequency Response:

2.1.6 Mounted Resonance Frequency:

2.1.7 Damping:

2.1.8 Transverse Sensitivity:

2.1.9 Temperature Response:

Compensated Range:

Thermal Sensitivity Shift:

Thermal Zero Shift: $\pm 2500 \mathrm{~g}$

$\pm 250 \mathrm{mv}$ nominal

$\pm 2 \%$ of reading to $3000 \mathrm{~g}$ (sinusoidal and shock)

Infinite

$\pm 5 \%, 0$ to $6000 \mathrm{cps}$

$30 \mathrm{~K}$ cps nominal

Approx. 0.03 critical

$3 \%$ maximum $(0.0012 \% \mathrm{FS} / \mathrm{g})$

in any transverse axis

$-65^{\circ}$ to $+250^{\circ} \mathrm{F}$

$0-03 \% /{ }^{\circ} \mathrm{F}$ maximum

$0.2 \% \mathrm{FS} /{ }^{\circ} \mathrm{F}$ 


\subsection{Electrical}

2.2.1 Rated Excitation:

2.2.2 Resistance (RT)

Input:

Output:

2.2.3 Cable:

10 v DC

2.2.4 Insulation Resistance:

510 ohm nominal

$330 \mathrm{ohm}$ nominal

Integral, 4 conductor with

shield and jacket. Shield

connected to case.

Greater than 100 megohms at 100 v DC

\section{B. Signal Conditioning Amplifier}

The amplifier used in this system had to meet the following specifi cations.

1. It must be compatible with a standard FMIFM telemetry system, i.e., its output should be from 0 - 5 volts.

2. The amplifier should have the capability of either linear or nonlinear operation. This means that the amplifier must be able to provide either a fixed gain or a gain that varies logarithmically with input so that the entire 5000-g capability of the Endevco Model 2261 accelerometer can be utilized.

3. The amplifier must be compatible with the Endevco Model 2261 gauge. This gauge produces a $0-500 \mathrm{mv}$ output from a source impedance of $250 \mathrm{ohms}$.

4. The 2261 gauge resonates at approximately $30 \mathrm{kc}$ and it was desired to cut the frequency response of the amplifier at $5 \mathrm{kc}$.

5. The system should be compatible with whatever power source can be made available to it.

These problems were analyzed and it was decided that an operational amplifier approach should be taken. The circuit for this system is shown in Figure 3a. The only variable components in the system are $\mathrm{Z}_{\mathrm{F}}$ and $\mathrm{R}_{\mathrm{B}}$. $\mathrm{RB}$ is the bridge balancing resistor that is used to set the nonlinear (Logarithmic) operating point of the amplifier.

$\mathrm{Z}_{\mathrm{F}}$ is the feedback component and it is used to determine the gain of the amplifier. For the linear fixed-gain system a single resistor is selected so that the output of the amplifier will be 5 volts at a given peak input.

$\mathrm{Z}_{\mathrm{F}}=\mathrm{R}_{\mathrm{F}}$ would be chosen from the equation

$$
A \approx \frac{R_{F}}{R_{i}}
$$


where $\mathrm{A}$ is the gain necessary to produce 5 volts out at maximum input. Equation 1 is the standard operational amplifier gain equation and it is based primarily on the assumption that the open loop amplifier gain is very large.

The situation for the nonlinear amplifier is practically the same. The feedback component $Z_{\mathrm{F}}$, however, becomes a network such as is shown in Figure $3 \mathrm{~b}$. The resistor values are chosen so that the current through the network becomes an approximate logarithmic function of the voltage across the network; thus, the amplifier with this feedback network has a logarithmic gain curve. Such a gain curve is shown in Figure 4, along with the feedback network used to produce that curve. The maximum and minimum gains are easily calculated provided that the outputs desired for minimum and maximum inputs are known. Knowing these gains and using Equation 1, the value of the resistor $\mathrm{R}$ and the total resistance can be calculated. That is, if $\mathrm{A}$ is the amplifier gain, then

$$
A_{\text {minimum }}=\frac{\max . \text { output }}{\max . \text { input }}=\frac{R}{R_{i}}
$$

or

$$
R=A_{\text {minimum }}\left(R_{i}\right)
$$

and

$$
\begin{aligned}
A_{\text {maximum }} & =\frac{\text { min. output }}{\text { min. input }}=\frac{R_{\text {total }}}{R_{i}} \\
R_{T} & =A_{\text {maximum }}\left(R_{i}\right)
\end{aligned}
$$

Then, if the accuracy of the approximation is known, the total number of diode resistor pairs is known; and from the slope of the gain curve, the other resistor values can be calculated. The calculations for the feedback network are based on the assumption of ideal diodes. Since the diodes are not ideal, a small error is introduced. The fact that the diodes are not ideal also smooths the curve so that the break points do not stand out.

The Fairchild MA702A in the TO-5 configuration was chosen to be the amplifier used in this system because of its electrical characteristics and its size. The power source used with the system must supply 20 to 24 volts at 40 milliamperes. This requirement supplies not only the signal conditioner but also the excitation for the gauge and the power for the voltage-controlled oscillator as shown in Figure 3. The voltage regulator used here is of the simple zener diode variety. The component values, voltages, etc., are shown in Figure 3 . This signal conditioner was designed around +5 volts as a reference so that the accelerometer could be DC coupled to the amplifier. The roll-off capacitor, shown as $\mathrm{C}-1$ in Figure 3 was selected to roll the frequency response curve off at $5 \mathrm{kc}$. The rate of roll off is $6 \mathrm{db}$ per octave. 


\section{VCO}

The Vector Division, United Aircraft, MMO-11 voltage-controlled oscillator was selected for this application primarily due to its small size and its inherent resistance to high shock loadings. To further increase the shock capability of the MMO-11, Vector was requested to epoxy encapsulate the substrate board to which the microminiature integrated circuits are affixed.

Frequencies selected for this application were Channels D and E (52.5 kc and $70 \mathrm{kc}$ $\pm 15 \%)$.

The VCO is mounted in the transducer and operational amplifier package and is encapsulated in Hysol Epoxy (Figures 5 and 7). In order for the unit to fit in our mounting configuration, it was necessary to grind off the mounting flanges.

Shock tests at levels up to $7500 \mathrm{~g}$ (half sine, $1 \mathrm{msec}$ ) in the longitudinal axis shaved no measurable deviations from standard parameters.

\section{Ag C1 Battery}

1. A market survey was conducted to determine the best possible power source for this application. After analyzing the volume available for the battery and the operational characteristics required for this application, the following parameters were established.

Nominal voltage

Rate

Capacity

Weight

Length

Diameter

Shock
24 volts

$100 \mathrm{ma}$

$50 \mathrm{mah}$

40 grams

1.85 inches

0.995 inch

$7500 \mathrm{~g} 1 \mathrm{~s}$, half sine, $1 \mathrm{msec}$.

As a result of the market survey, two types of batteries were selected that met some or all of the above listed specifications. These were the silver cell and the water activated silver chloride cell. The latter was selected due to the physical structure of the plates and their adaptability toward high-shock packaging.

A contract was placed with Eagle-Picher Company, Precision Product Plant, Socorro, New Mexico, and as a result, a battery was designed which was compatible with the other components in the system as we" as the above listed specifications. 
Figures 6 and 8 show the physical configuration, including the Elco connector and guide pin which allowed for blind insertion of the battery and operational amplifier in the penetrometer.

2. The battery receives its formation charge by immersing it in water for a 1-minute period, after which a 100 ma load is placed on the battery for a period of 5 minutes. Felt pads are then placed in the fill slots and the battery is ready for use.

3. Chemical data. The cathode reaction is a silver chloride reduction:

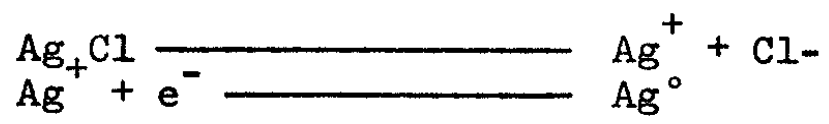

Anode reaction is an oxidation of Dow Chemical Company magnesium alloy Az-31B:

$\mathrm{Mg}^{\circ}+2 \mathrm{Cl}^{-}-\mathrm{Mg} \mathrm{Cl}_{2}+2 \mathrm{e}^{-}$

4. This battery, as shown in Figure 8 is encapsulated in solid epoxy. Shock tests at levels in excess of $7500 \mathrm{~g}$ 's showed a transient voltage loss of less than 5 percent during shock, which will not affect the performance of the system. Figure 9 shows the battery response to a 7500-g shock input. Capacity of this battery can be increased up to 40 percent by decreasing the amount of compressive load on the plates; however, its resistance to shock loadings falls off proportionately.

\section{E. Transmitter}

A survey of telemetry transmitter manufacturers resulted in Conic Corporation, San Diego, California, being selected to design and manufacture a 2.4" x 1" diameter transmitter capable of producing $100 \mathrm{mw}$ and withstanding severe shock loads up to $10,000 \mathrm{~g}$ 's.

The design concept centered around the modulator circuit from the Conic CTM 400 series of 215 - $265 \mathrm{mc}$ transmitters. These transmitters utilized an IC voltage-controlled oscillator with a center frequency of approximately $20 \mathrm{mc}$.

In addition to the above-mentioned LC VCO, a buffer amplifier, power amplifier, and an output bandpass filter were designed and checked out in breadboard form. All components were chosen with the shock environment in mind, including encapsulated inductors and capacitors. The circuits were then mounted in cordwood form between two printed circuitboards running in the longitudinal direction. The module was then firmly attached to an aluminum longitudinal keel strength member and encapsulated with highstrength configuration polyurethane. A Selectro SK-14 connector was mounted in the transmitter for coupling to the antenna (Figures 10 and 11). 
The buffer amplifier serves to minimize the effects of antenna reflection and voltage perturbations in regard to frequency stability. Modulation frequency response is DC to $500 \mathrm{kc}( \pm 3 \mathrm{db})$. The transmitter was designated by Conic as the CTM 400.25.

\section{CTM 400.25 Transmitter Specifications}

$\begin{array}{ll}\text { 1. Power Output } & 100 \mathrm{mw} \text { nominal } \\ \text { 2. Voltage Input } & 22 \mathrm{v} \pm 10 \% \\ \text { 3. Current Input } & 40 \mathrm{ma} \\ \text { 4. Temperature } & 0^{\circ} \text { to }+60^{\circ} \mathrm{C} \\ \text { 5. Frequency } & 19.8 \mathrm{mc} \pm 50 \mathrm{kc} \text { max. } \\ \text { 6. Frequency Stability } & 0.01 \%\end{array}$

This transmitter has been shocked at levels up to $7500 \mathrm{~g}$ 's (half sine, $1 \mathrm{msec}$ ) with frequency perturbations of less than $10 \mathrm{kc}$.

Although this transmitter was designed as a true FM unit, it was felt that the VCO modulation technique would be preferable due to the possibility of small carrier frequency shifts under severe shock loadings.

\section{F. Antenna}

The selection of a transmitter operating on a $19.8 \mathrm{mc}$ carrier frequency presented several antenna design problems. The antenna would have to survive high-shock loadings and be of such physical configuration as to not adversely affect the penetrometer flight performance. In addition, it would have to radiate the $100 \mathrm{mw}$ output of the transmitter through both air and target materials with enough efficiency to insure adequate signal to the receiving antenna.

The physical size was established as a right circular cylinder, 4-1/2 inch in length and $3 / 4$ inch in diameter, with a pin and load ring supplied to make electrical contact to the transmitter. (Figure 12).

The antenna, which was designed by Division 1424, Sandia Corporation, was an autotransformed ferrite loopstick, with the components epoxied inside a fiberglass rod. The antenna presents a load to the transmitter of $50 \mathrm{ohms} \pm 5$ with a $\mathrm{j}$ factor of \pm 5 . The antenna efficiency is approximately $-10 \mathrm{db}$.

This completes the electrical and physical discussion of the individual components. With the exception of the signal conditioning module and the antenna, which are made by Sandia Corporation, the other components are now available as commercial products from the respective vendors. 
Operational Concepts The theory of projectile design and the interpretation of data will not be duscussed in this paper. We will now discuss the test facilities, receiving instrumentation and operational concepts utilized in this project.

\section{A. Test Facilities}

1. Sled Tracks -- Existing Sandia sled tracks were modified to incorporate a 1-1/4-inchdiameter slotted tube mounted above the rail. A rocket powered sled mounted on the rail accelerated the projectile in the tube by means of a push rod. The sled was decelerated by means of stopper foam and the projectile then free flighted into the target materials. There were virtually no pitch or yaw perturbations in the projectile flight profile.

Both vertical and horizontal sled configurations were used on this project.

2. Ground Station Instrumentation -- Quarter wave ground plane antennas were installed in close proximity to the targets to receive the $19.8 \mathrm{mc}$ transmitted signal. These antennas then feed an upconverter which Sandia designed to allow the use of standard frequency receivers. With the exception of the upconverter, the ground station instrumentation was standard (Figure 13).

The upconverter schematic is shown in Figure 14. It consists of a preamplifier stage, a crystal-controlled local oscillator and a mixer stage. This device beats the $19.8 \mathrm{mc}$ signal with a $215 \mathrm{mc}$ signal, resulting in a $234.8 \mathrm{mc}$ carrier which is then fed into a standard telemetry receiver. The combined upconverter/receiver sensitivity was approximately 3 Uv.

Due to the close proximity of the receiving antennas, there has been no lack of signal strength on any of the more than 100 tests on this program. Typical signal strength when firing through targets with a percent lead content is $2000 \mathrm{uv}$.

3. Camera Coverage -- High speed image motion photography taken just prior to entry into the first target gives us a velocity reading with 1 percent accuracy. Fastex camera coverage gives angle-of-attack and soil-deformation data.

4. Data Reduction -- The test tape is digitized by the Epsco process and is fed into computers for analysis and plotting. Four data plots are used for each event: acceleration vs. time, the first integration of $\mathrm{A} / \mathrm{T}$ (or velocity) vs. time, the second integration (displacement) vs. time, and $\Delta$ acceleration vs. $\Delta$ velocity. 


\section{B. System Operation}

The assembly, calibration, and operation of the accelerometer package will be described below in sequence form as pertains to a typical rocket sled shot.

1. Select transducer and signal conditioning module for desired g range. Either a linear or a nonlinear package will be chosen depending on the degree of knowledge concerning anticipated shock levels.

2. Dynamically calibrate the package on a vertical actuator to the anticipated g levels. By means of calibrated reference gauges and oscilloscope pictures, the sensitivity of the package is established in terms of millivolts per $\mathrm{g}$.

3. The package is now taken to the firing area and a five-step spin cal is transmitted to the ground station and recorded. Signal-tonoise ratio of the VCO carrier is monitored on a spectrum analyzer. Typical readings for this system are in the $35-40 \mathrm{db}$ range.

By means of an RF attenuator, a signal strength step cal is recorded on tape.

4. Targets are selected and placed in position.

5. The rocket sled is positioned and the firing circuits and camera signals are verified.

6. After the $\mathrm{Ag} \mathrm{Cl}$ battery is activated, the package is installed in the projectile and placed in the launching tube.

7. The rockets are armed and the ground station is prepared to receive the transmitted signal.

8. After receipt of command from the ground station operator, the sled is fired and the projectile is accelerated into the target array; at which time the transmitted signal is recorded and displayed for quick-look analysis.

9. After the projectile is recovered, the unit is post calibrated as described in Step 2.

10. After the calibration is verified, the shot tapes are sent to the data reduction organization where they are reduced and plotted. Typical shot records are shown in Figures 15, 16, 17, and 18.

Figure 16 is the first integration of Figure 15 (velocity) and Figure 17 is the second integration (displacement). The initial velocity on this particular shot was 315 feet per second, which was verified by image motion camera data. 
Conclusion This paper has described the development of a system capable of measuring deceleration profiles in the $0-10,000 \mathrm{~g}$ range. Since February 1965, there have been approximately 100 firings of the system described. In this number of tests there have been no transmitter, VCO, battery, antenna, or signal conditioning failures. On several occasions, gauge failures have occurred when the environmental limits of the gauge have been accidentally exceeded.

The principal problem encountered has been in the area of gauge resonance and considerable testing was accomplished to verify the validity of filtering techniques and their effects on data.

This system is currently being incorporated into gun-test facilities and, at this time, we have not encountered any serious problems in this area.

Acknowledgment The author gratefully acknowledges the assistance given by the members of this project and the people vho have given support to us. In particular, I would Like to single out Messrs. J. M. May, J. K. Ovens, W. R. Pfarner, C. O. Duimstra, P. B. Herrington, C. H. Senter, D. R. Wilkinson, P. B. Brumley, and R. A. Hastings.

In addition, I would like to acknowledge the outstanding support from personnel at the Sandia Shock and Track Department (7340), the Photometrics Division (7226), and Data Reduction (7216 and 7267).

The vendors involved, Conic Corporation, Endevco Corporation, Vector Division of United Aircraft, and Eagle-Picher Company were most cooperative. 


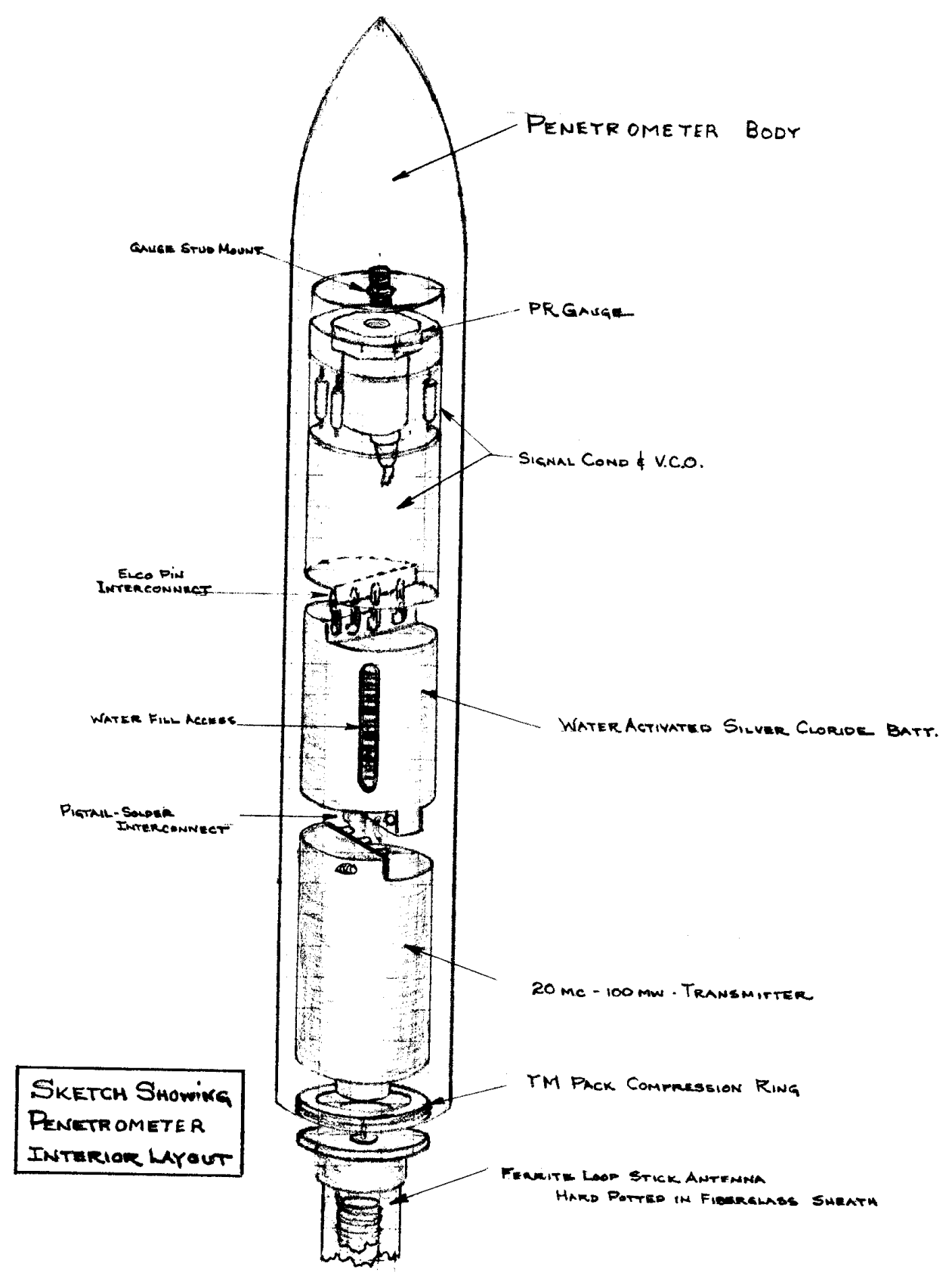

Figure 1. Accelerometer Package Assembly Drawing 


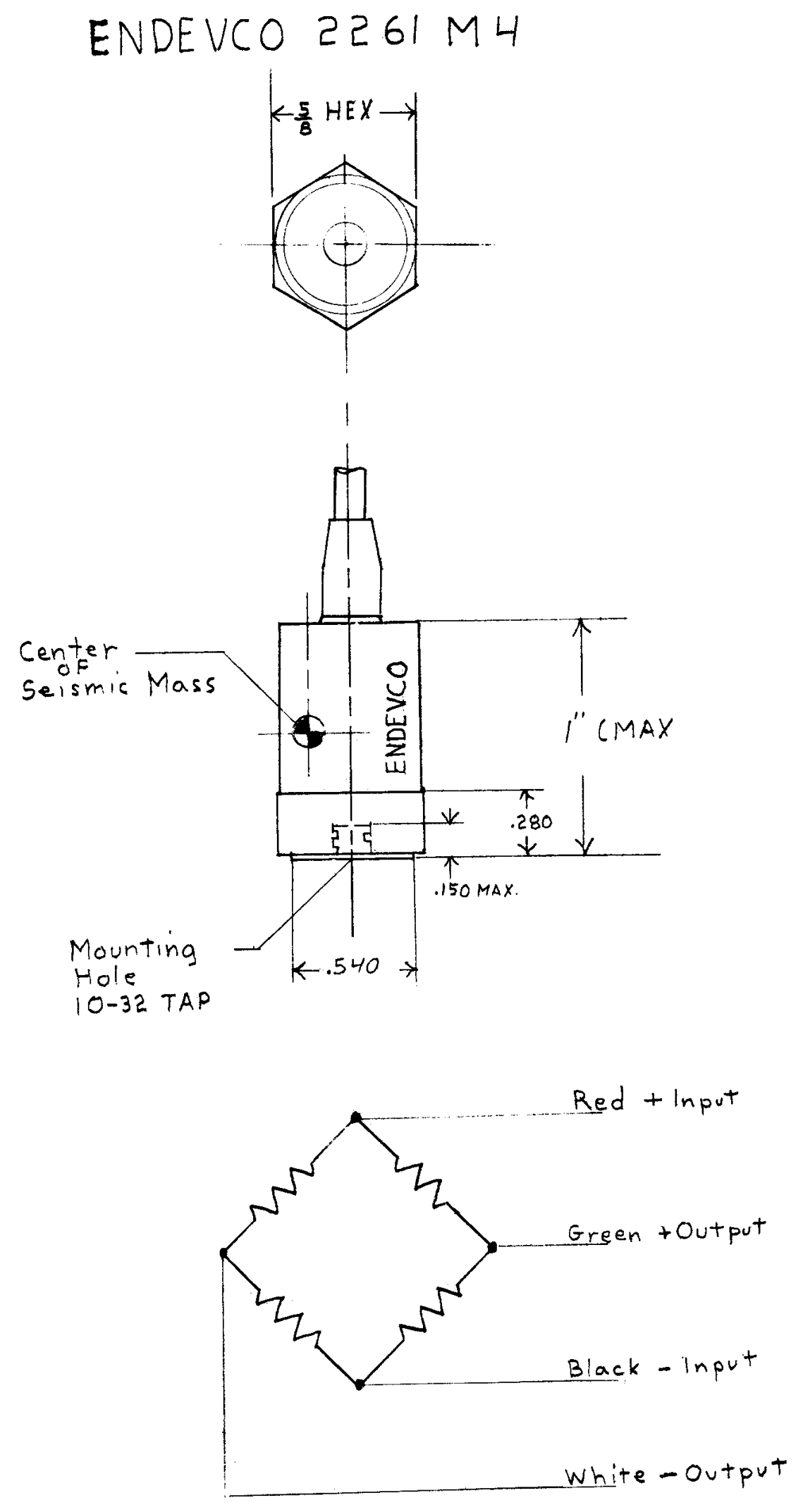

Figure 2. Endevco 2261-M4 Piezoresistive Accelerometer 


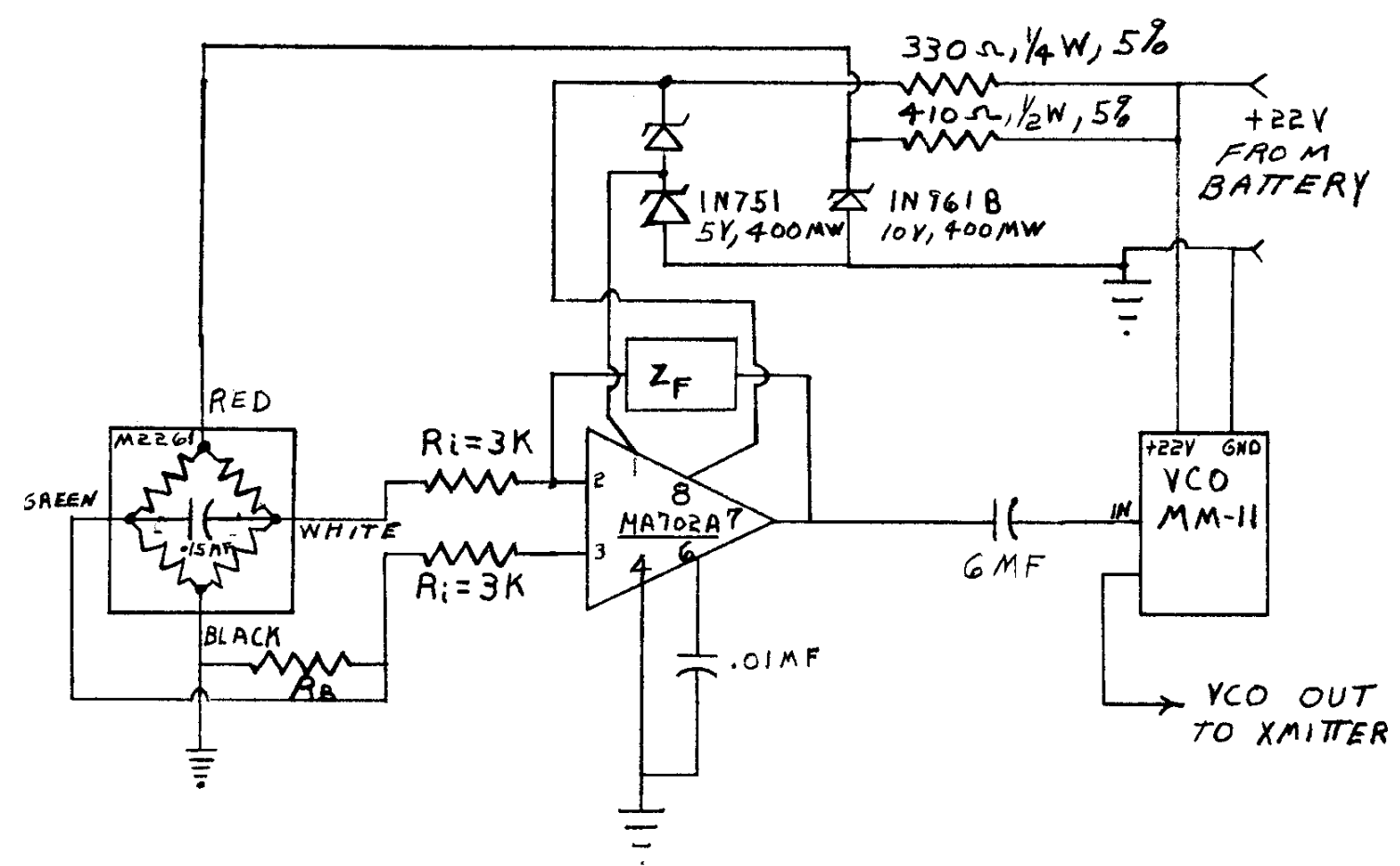

a. TRANSDUCER, VCO, AND SIGNAL CONDITIONER.

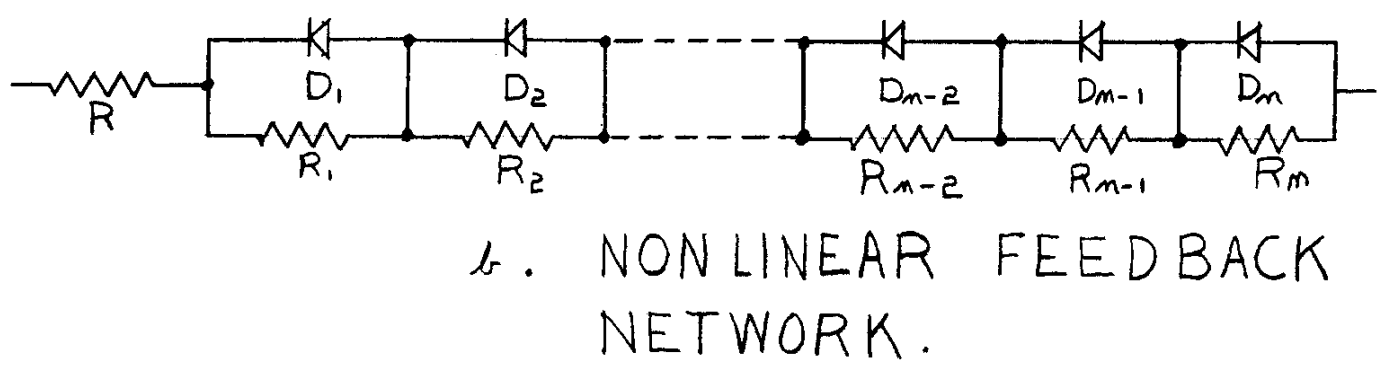

Figures 3a \& 3b. Signal-Conditioning Amplifier \& Nonlinear Feedback Network 


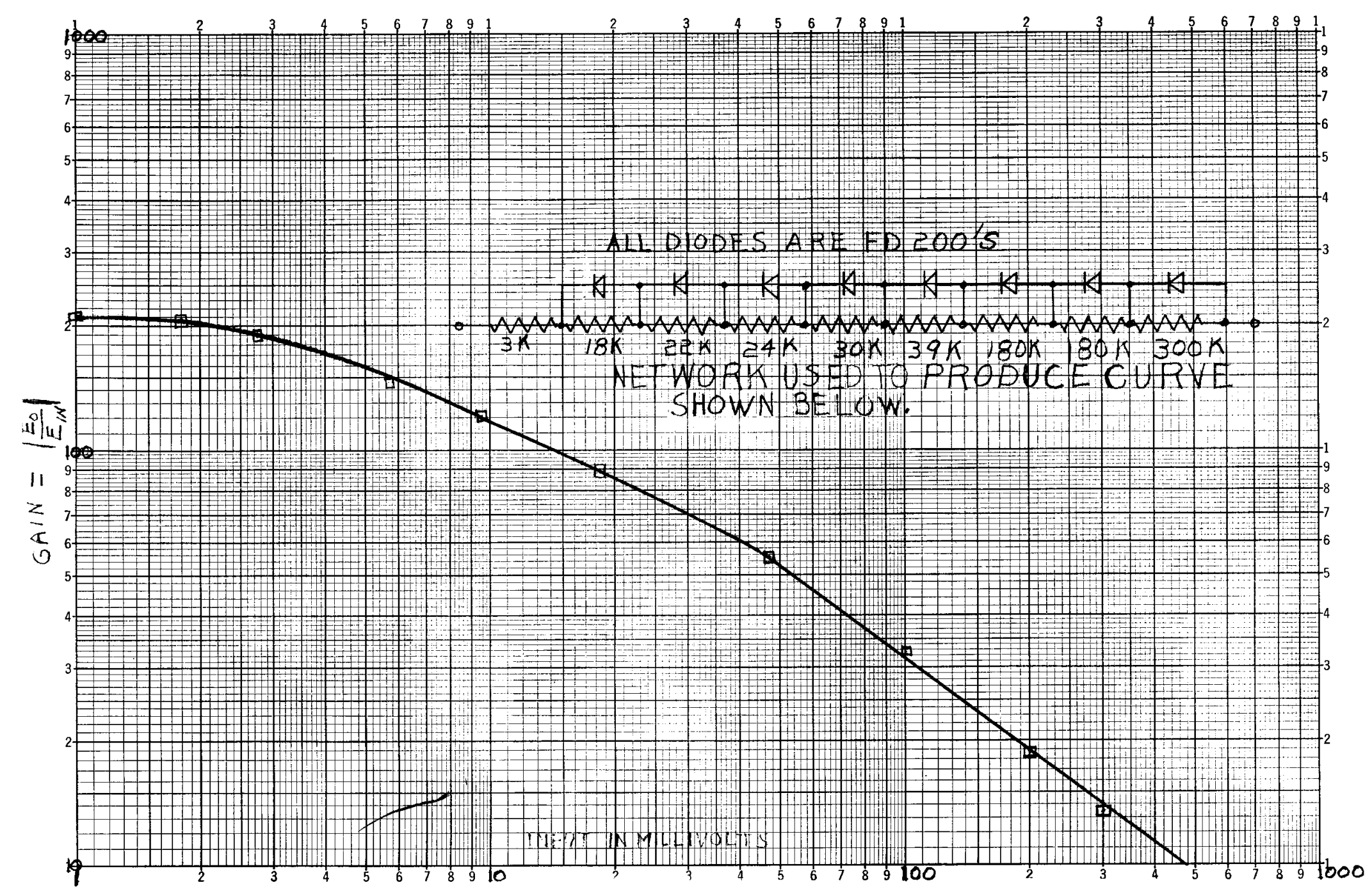

Figure 4. Gain Curve of Nonlinear Operational Amplifier As A Function of Input 

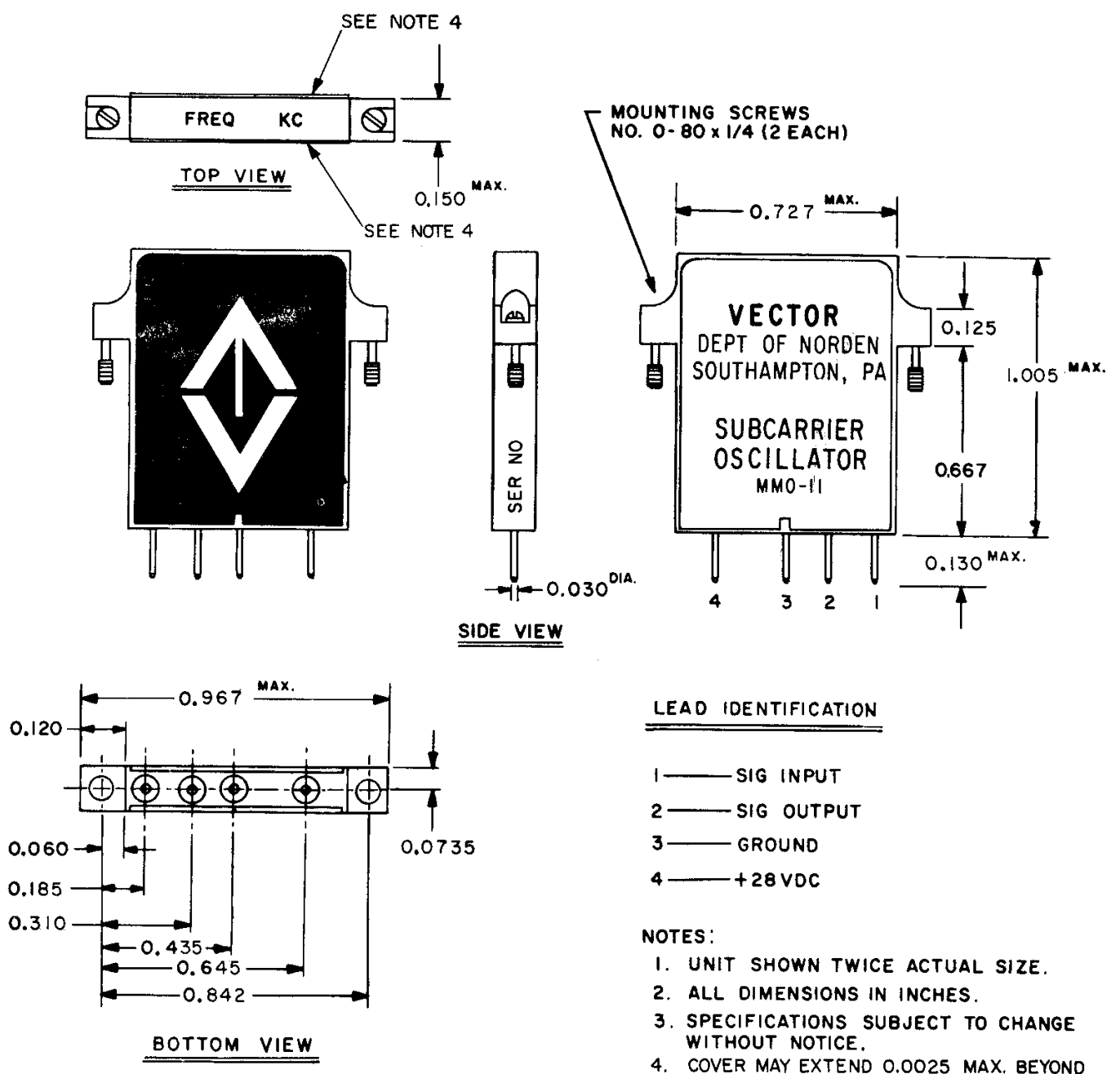

NOTES:

1. UNIT SHOWN TWICE ACTUAL SIZE.

2. ALL DIMENSIONS IN INCHES.

3. SPECIFICATIONS SUBJECT TO CHANGE WITHOUT NOTICE.

4. COVER MAY EXTEND 0.0025 MAX. BEYOND SURFACE OF CASE.

SUBCARRIER OSCILLATOR, MODEL MMO-II, OUTLINE DRAWING AND LEAD IDENTIFICATION.

Figure 5. Vector MMO-11 Microminiature Voltage-Controlled Oscillator

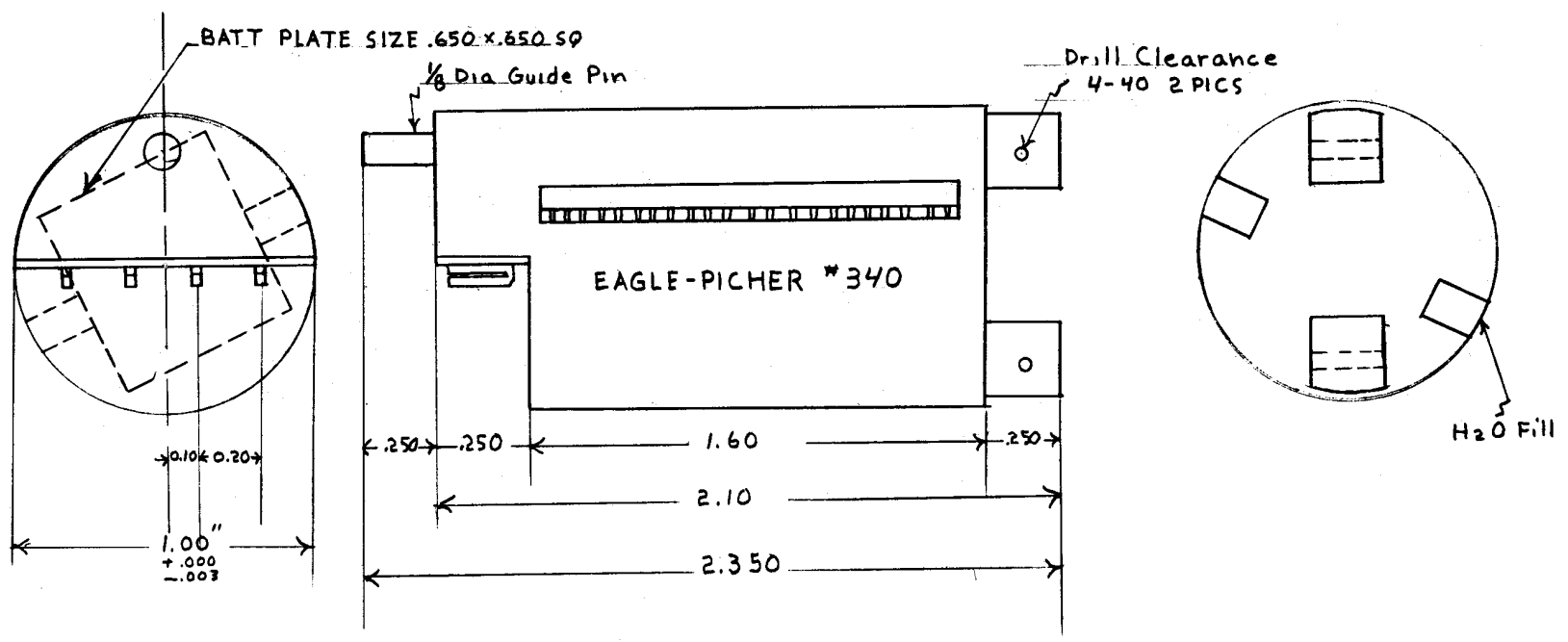

Figure 6. Eagle-picher model 340 Silver Chloride Battery 

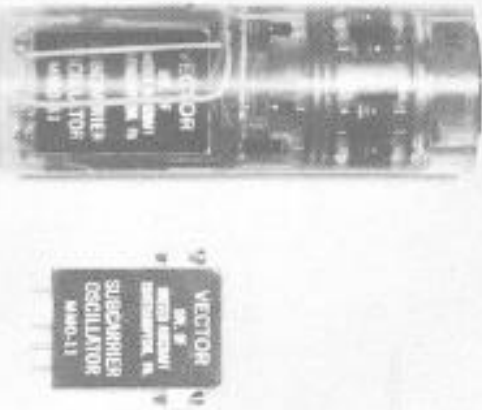

Figure 7. Signal-Conditioning Module and VCO
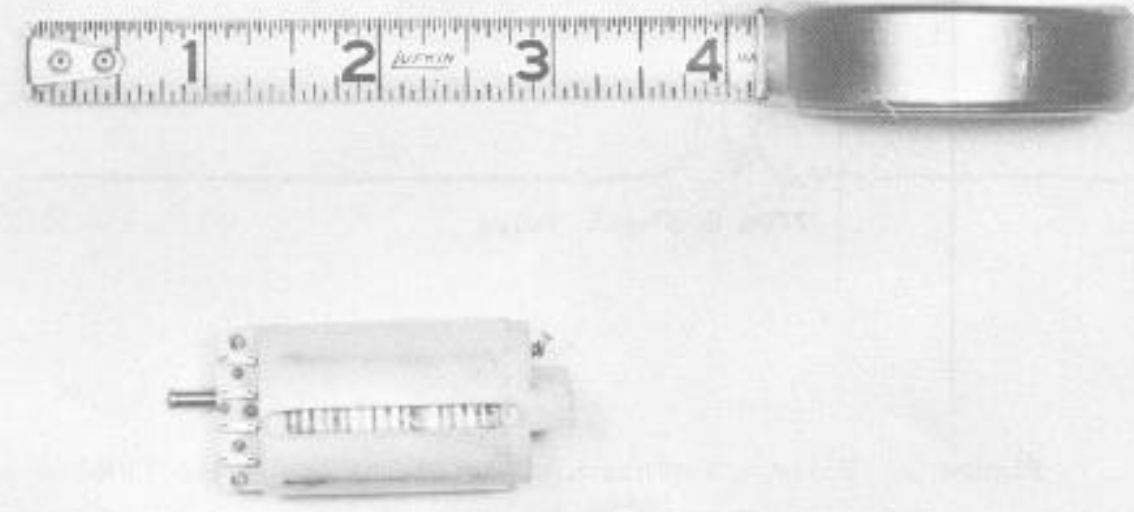

Figure 8. Eagle-Picher Model 340 Ag C1 Battery 


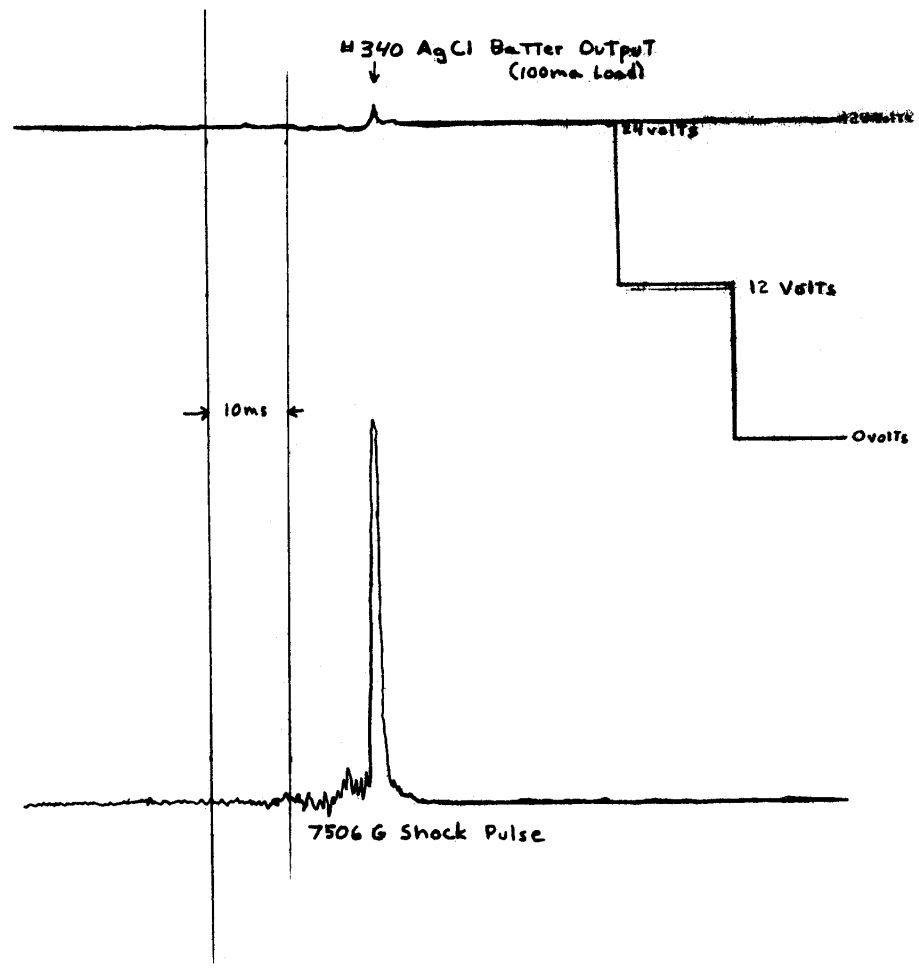

Figure 9. Voltage Variation of Ag Cl Battery Under 7506G Shock Impulse
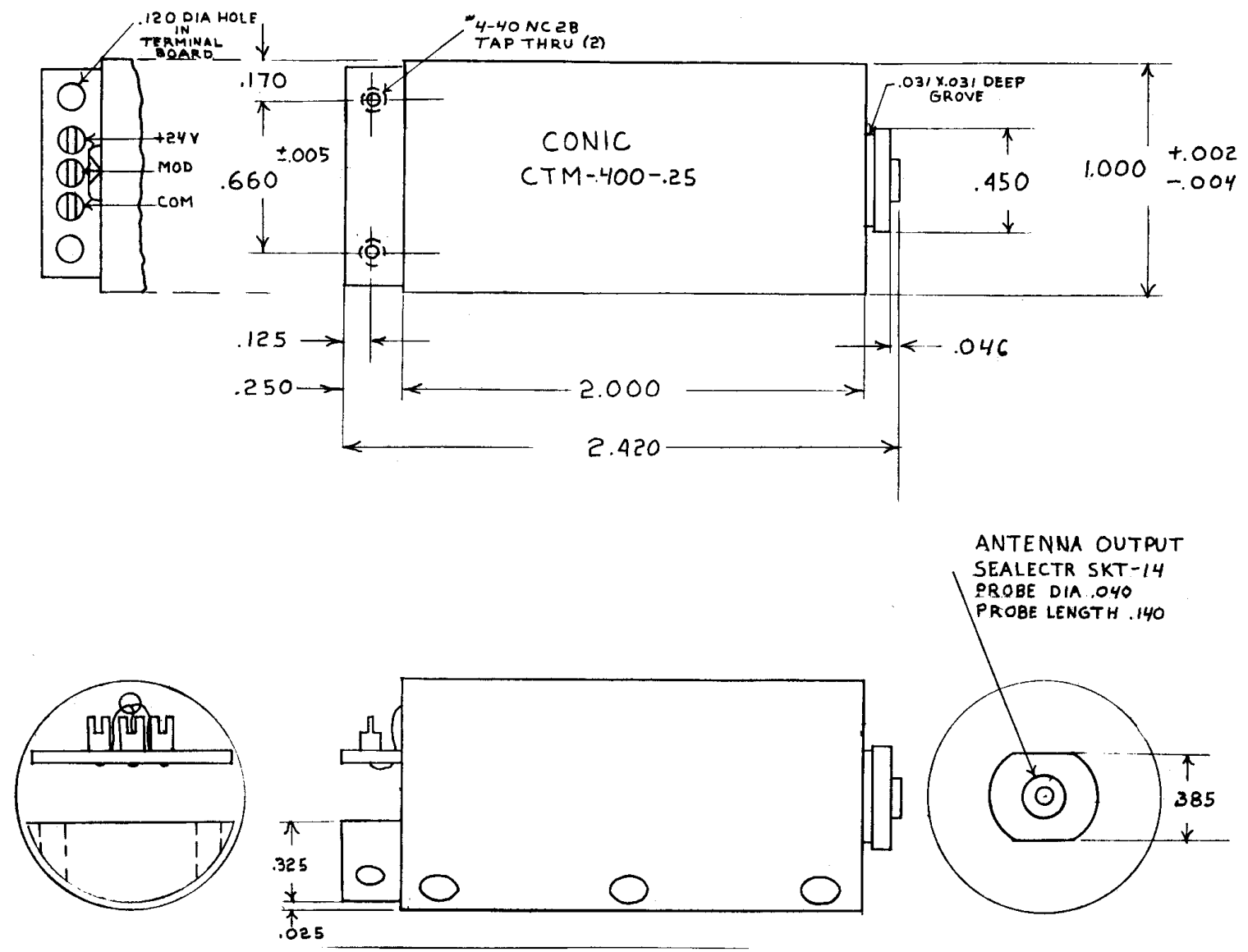

Figure 10. Conic CTM-400,25 19.8 mc Transmitter 

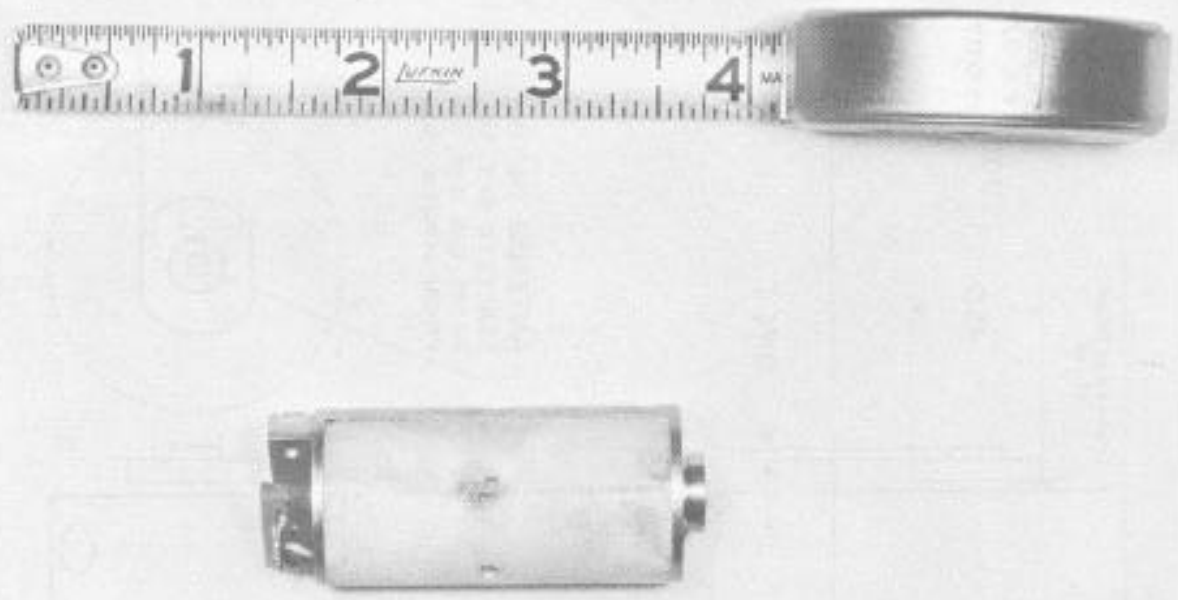

Figure 11. Conic CTM-400-.25 19.8 mc Transmitter

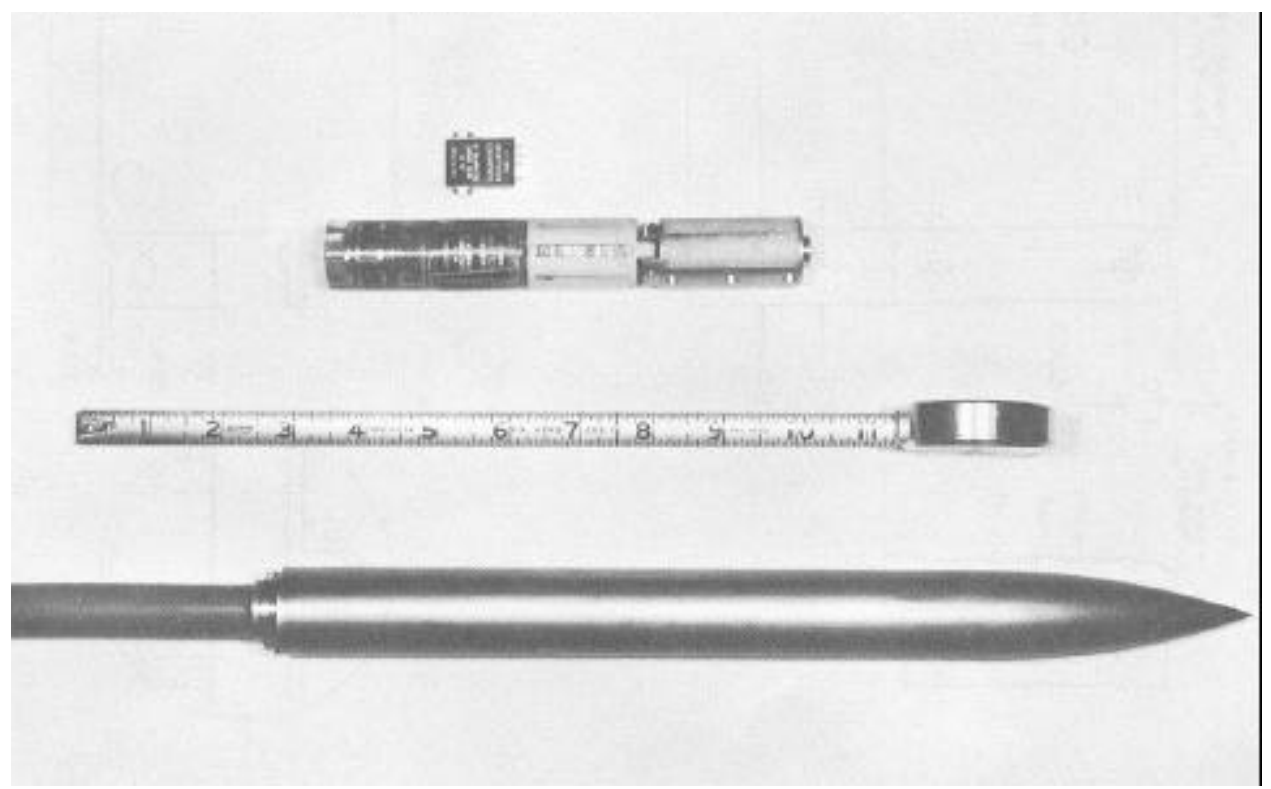

Figure 12. Projectile With Autotransformed Loopstick Antenna Installed 


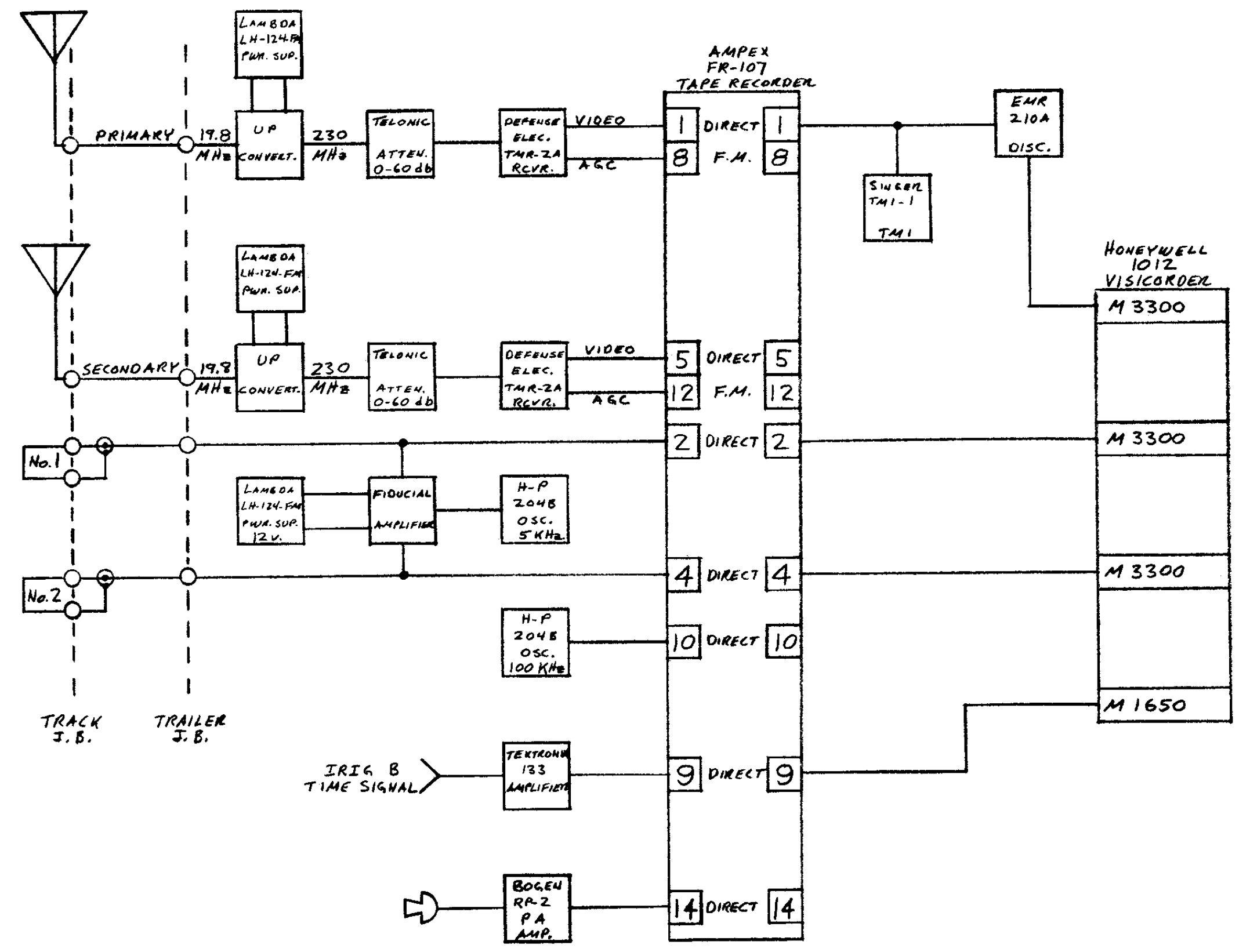

Figure 13. Ground Station Schematic 


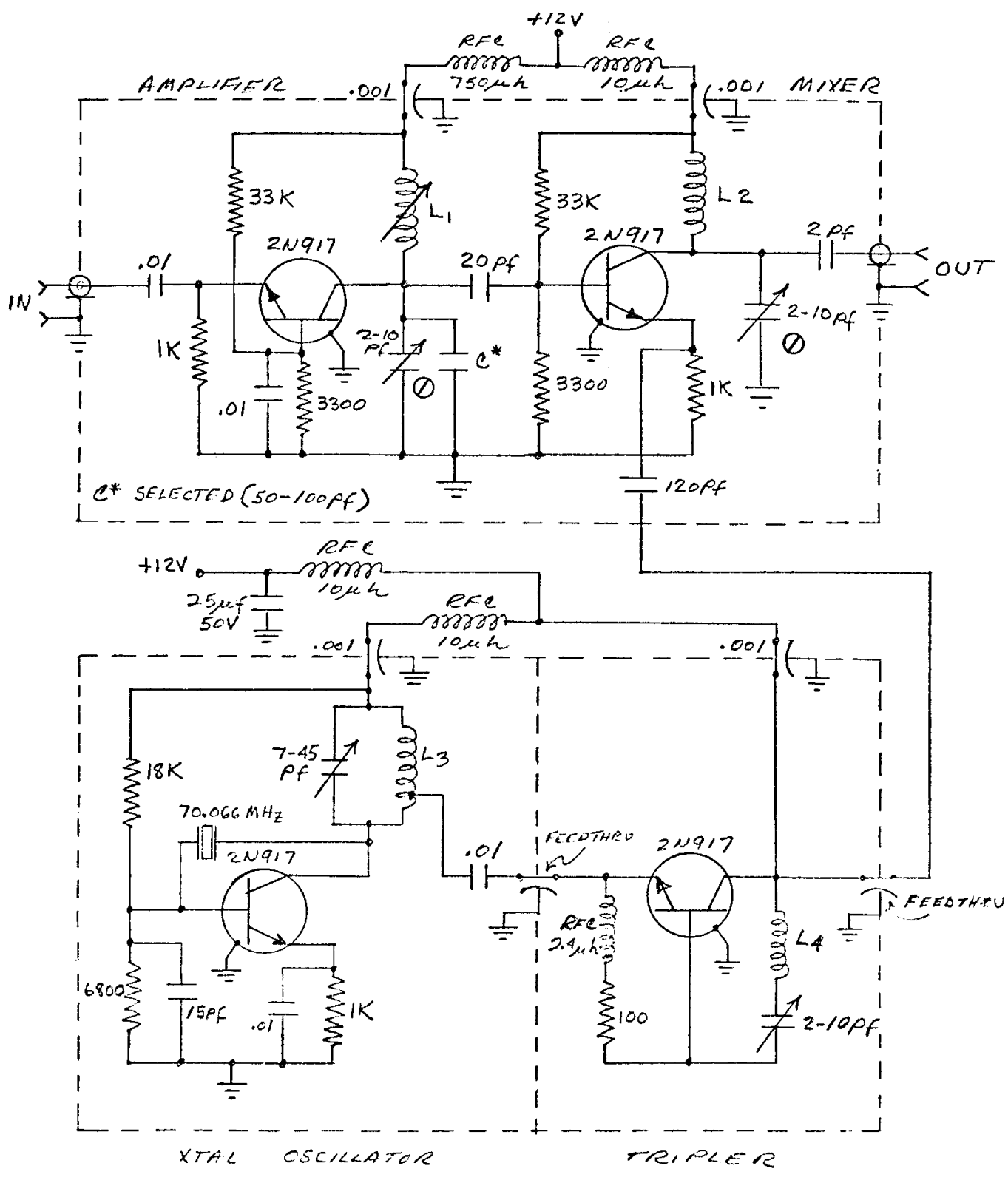

Figure 14. Upconverter Electrical Schematic 


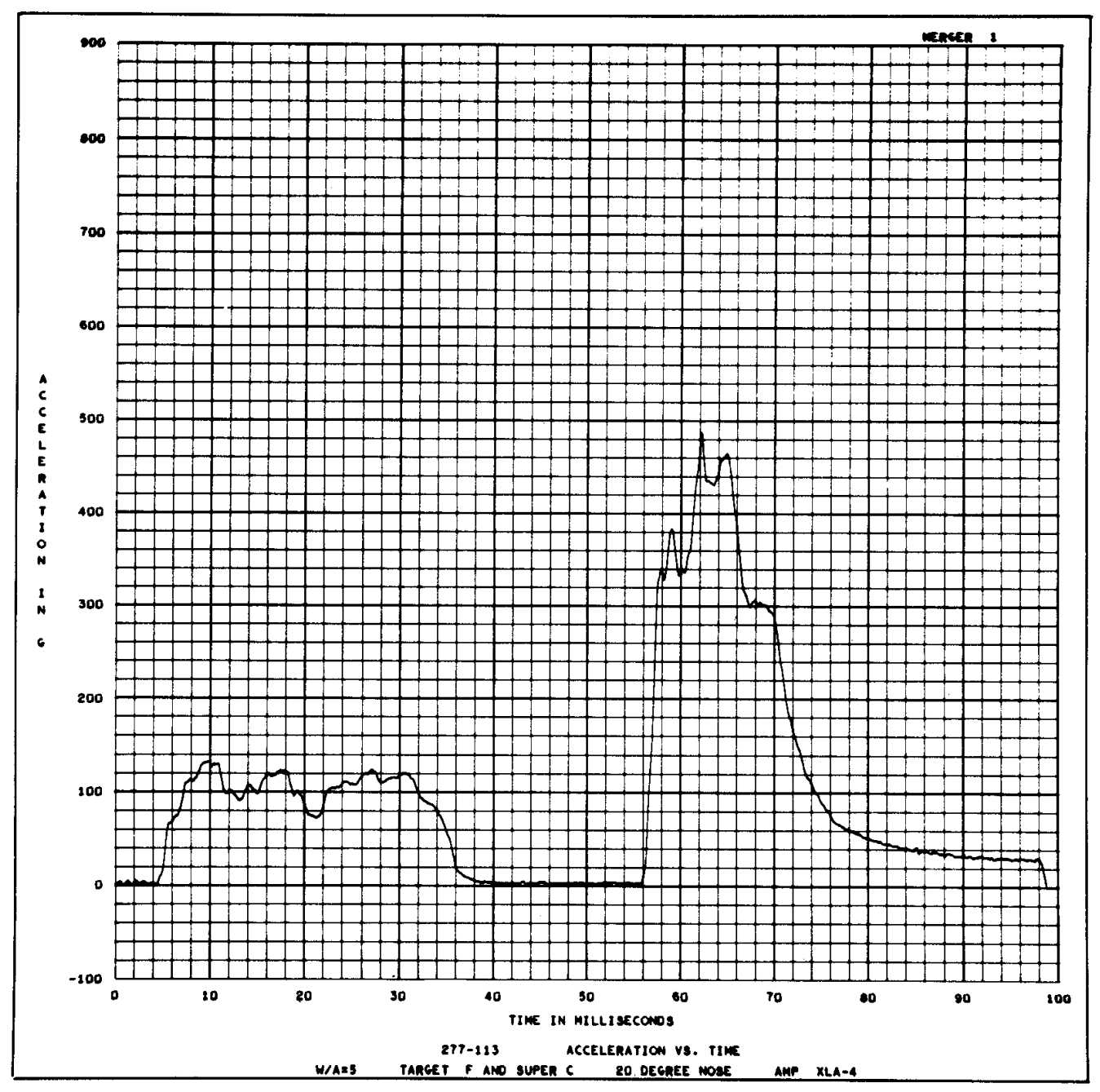

Figure 15. Acceleration Vs Time Plot 


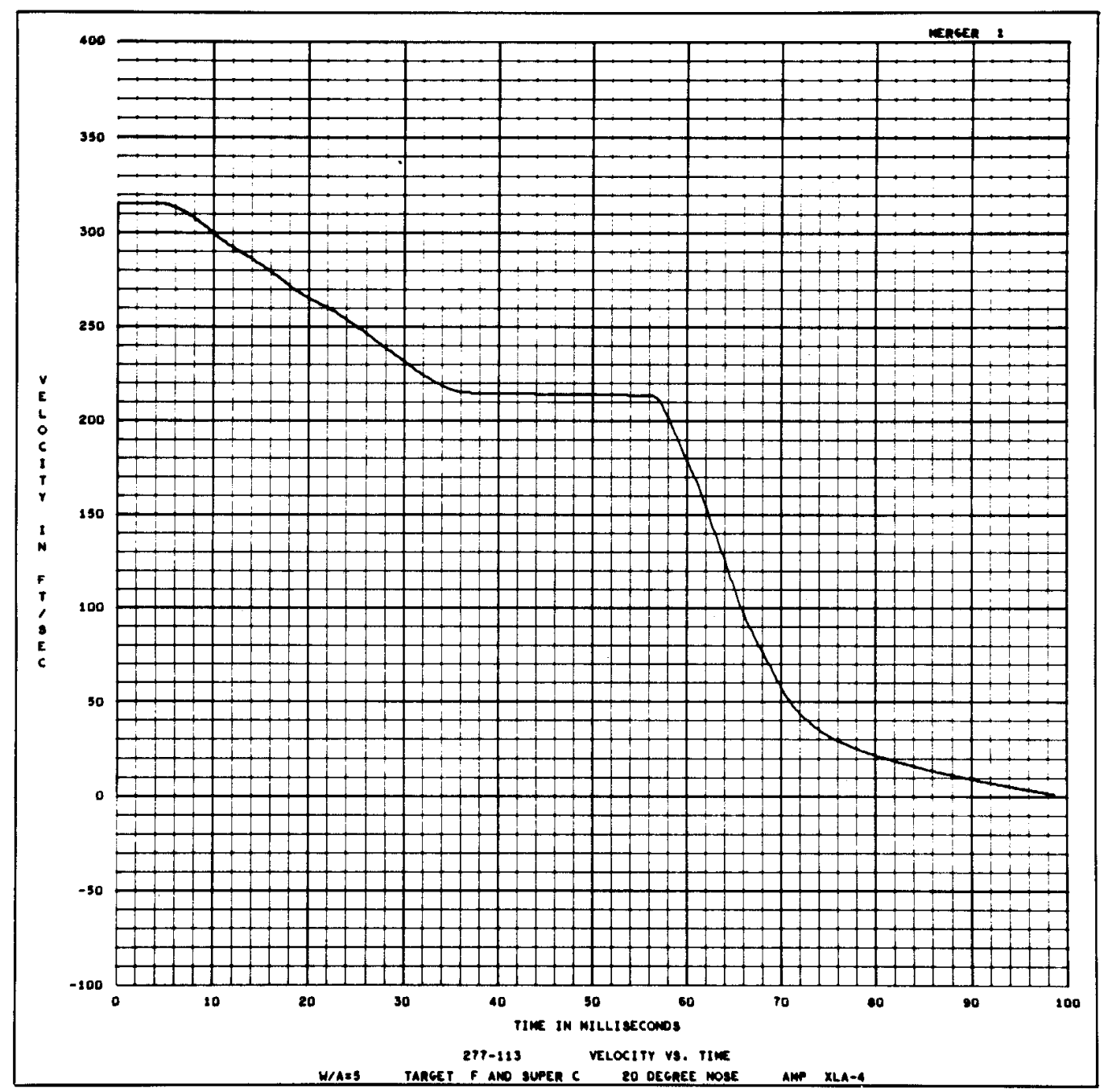

Figure 16. Velocity vs Time Plot 


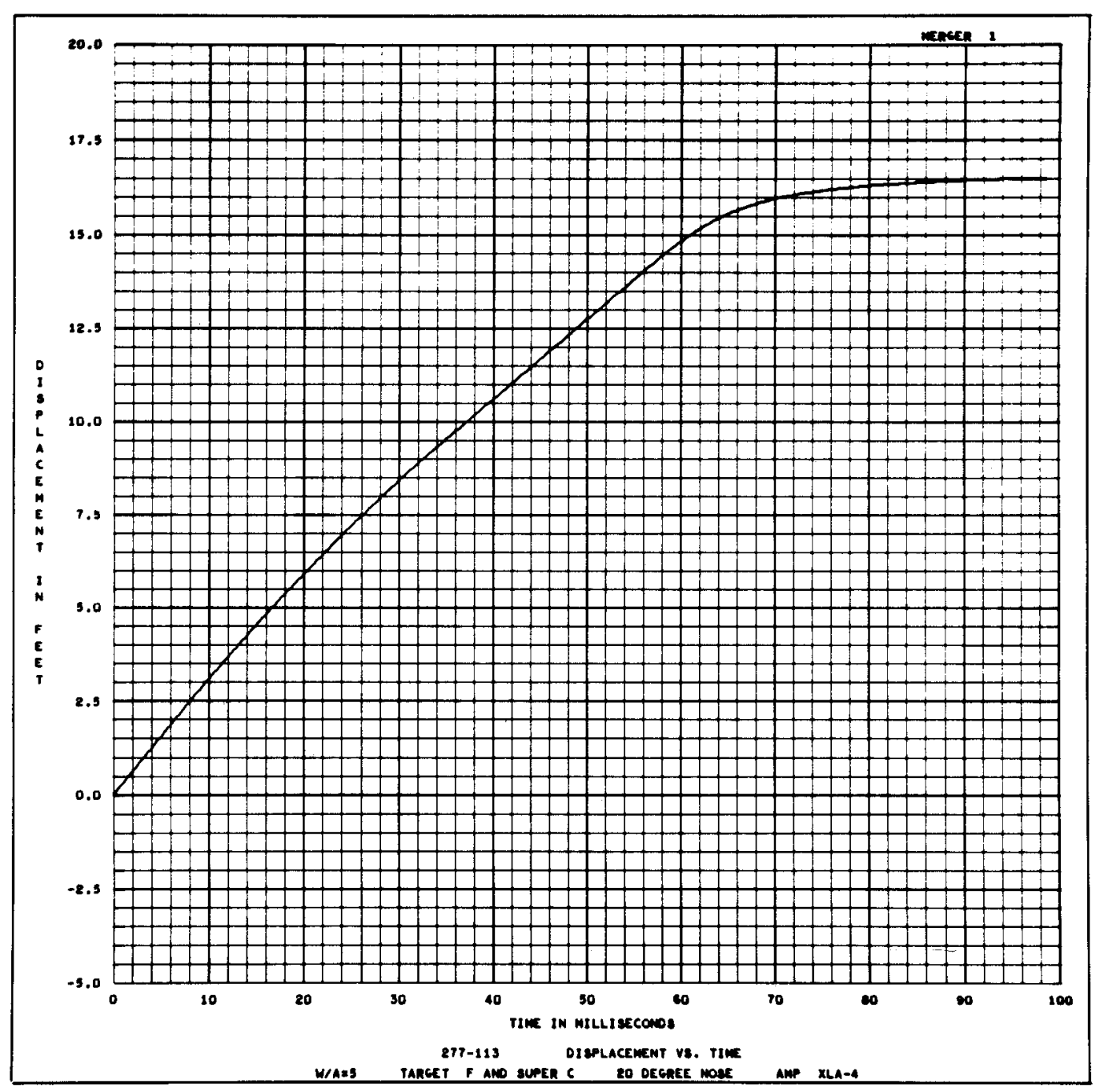

Figure 17. Displacement vs Time Plot 


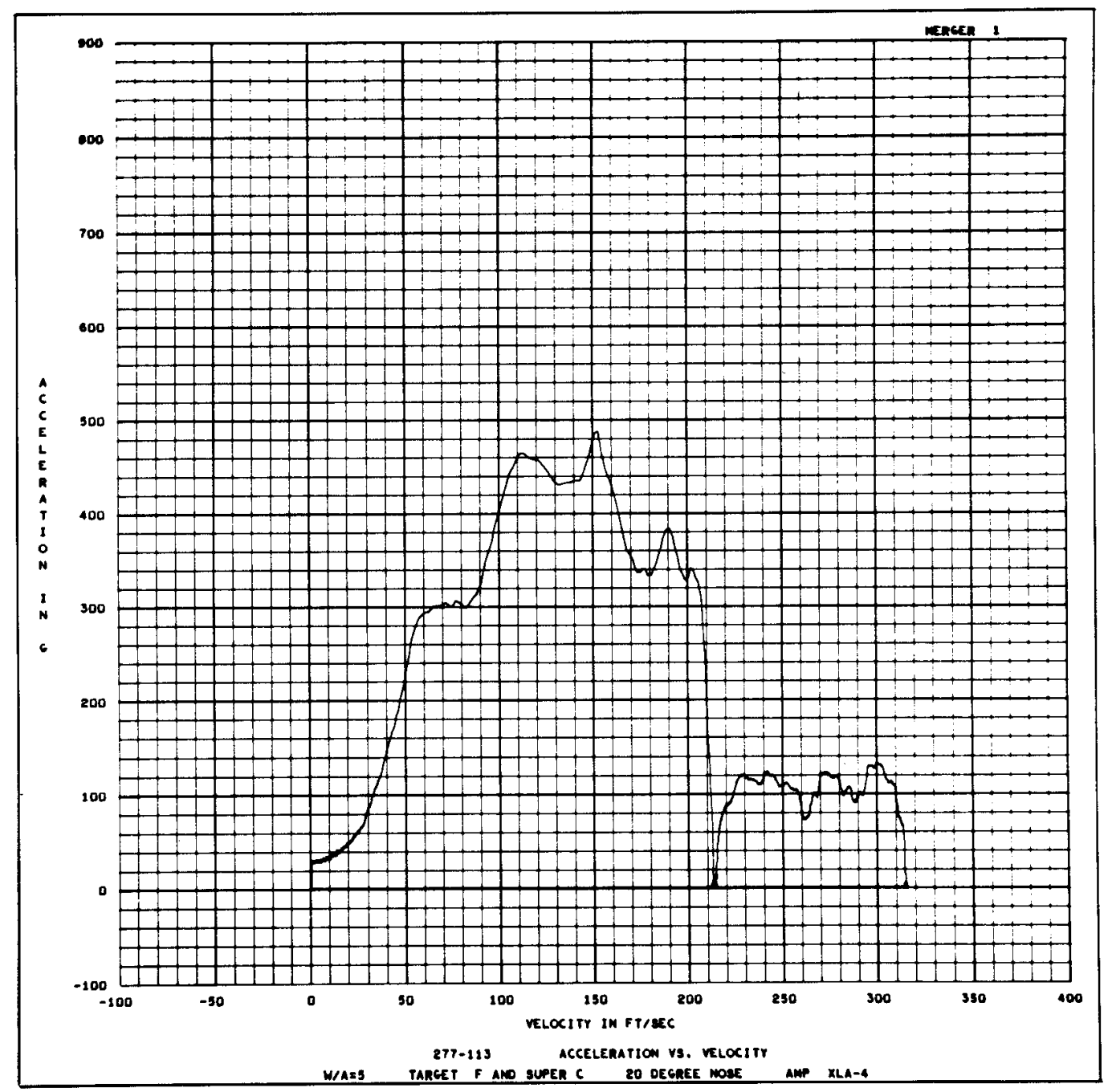

Figure 18. Acceleration vs Velocity Plot 